\title{
Strengthening Health Care in the Kurdistan Region of Iraq
}

\begin{abstract}
A fter the fall of Saddam Hussein, the leaders of the Kurdistan Regional Government (KRG) in Iraq needed to rebuild the area's economic and social
\end{abstract} infrastructure. The former regime had intentionally and systematically underfunded all sectors_-including health. With greater autonomy in 2008, the KRG moved to develop the region and improve its citizens' well-being. As part of that effort, it partnered with the RAND Corporation to study the region's situation, develop strategies, and help implement selected solutions. The work began with a focus on four areas-health, education, private-sector development, and employment-and later expanded to include the use of data to support policymaking and strategic planning. This research brief describes the RAND research team's health sector work.

Although Iraq had been a leader in health care among Middle Eastern countries before the first Gulf War (1990), the Hussein regime's persecution of the Kurdish region made it impossible to invest in buildings, equipment, and manpower necessary to sustain modern medical practice and support the needs of a growing population. The sacrifices of the two Gulf Wars took their toll. By 2010, the region's infant mortality rate had risen to a level higher than that of neighboring countries, signaling problems across the broad health system. Help was needed to swiftly and efficiently address problems-before they got worse.

\section{The Study}

The KRG and the RAND research team began working together in 2010 to develop short- and long-term strategies to improve the region's health care system. In three phases over six years, RAND Health researchers, working closely with the KRG's Minister of Health, Minister of Planning, and other leaders, analyzed the region's health care system and worked through goals and options for improvement by the year 2020 . The RAND team's comprehensive assessment included data collection and interviews with a wide array of stakeholders and policymakers and formed the basis for recommendations and plans for improving health care financing, primary care, and health service quality.

RAND researchers gathered new data during their assessment to supplement existing data from the KRG, and they developed models to establish a baseline of health resources

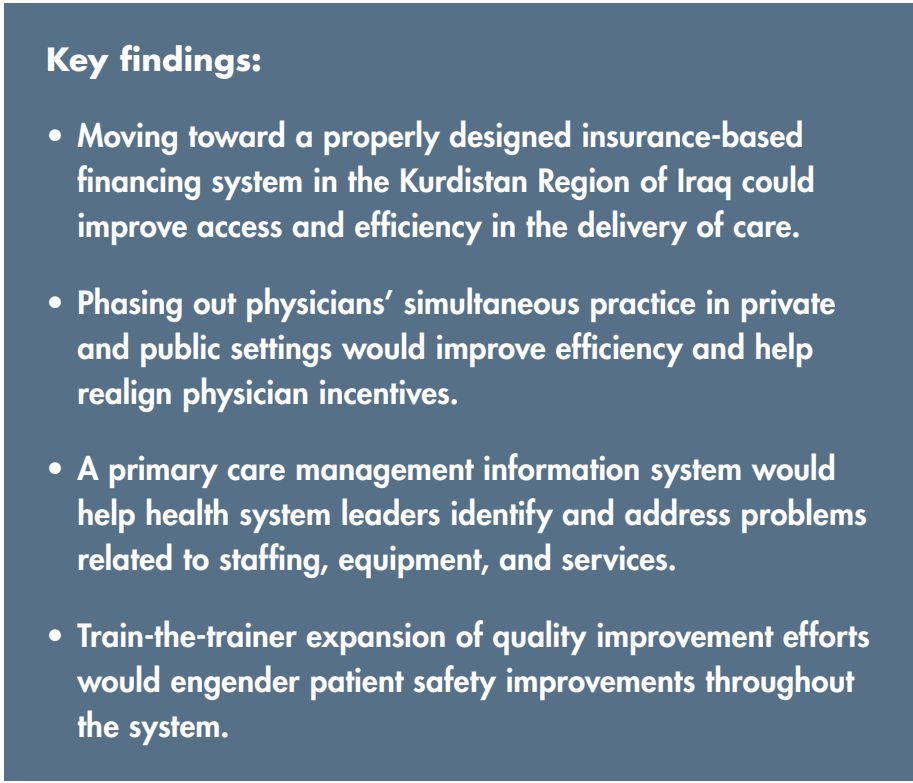

and project future demand for health care services. Using a number of population growth scenarios, the RAND team estimated demand for hospital beds and manpower necessary for the KRG's envisioned health care goals. The researchers found that, even under conservative growth models, by 2020 the KRG would need to increase capacity by more than 2,500 hospital beds, more than 2,000 physicians, more than 3,300 nurses, and almost 250 dentists. The research team also modeled improved primary care efficiency and growth of the private sector. All scenarios indicated that, in order to meet future needs and improve the system, significant investments in capital and manpower would be necessary.

Based on these assessments and comparisons with other countries, RAND researchers offered a handful of potential health care financing policy options, describing the advantages, disadvantages, and implementation steps for each. Researchers examined in detail one particular issue that impinges on health system financing and delivery efficiency in the region: the problem of physician "dual practice," in which physicians practice in the private sector while also being employed full-time in the public sector. In the area of primary care, the RAND team offered nearly 60 specific recommendations and then organized them by importance and feasibility to help prioritize early actions. Lastly, RAND 
researchers assessed the status of health service quality and recommended that the KRG adopt a comprehensive quality improvement agenda, beginning with a hospital patient safety program.

These joint efforts by the RAND team and the KRG serve as a foundation for building a stronger, more modern health care system by 2020 . In spite of the recent severe budget restrictions resulting from the invasion of Iraq by the Islamic State of Iraq and Syria (ISIS), the KRG began to implement some recommendations, as detailed later in this brief.

\section{Health Financing}

From the start of this project, KRG leaders and physicians alike informed the RAND team that health care services in the region were underfunded, had become inefficient, and needed to be assessed to identify problem areas and potential solutions.

The public-sector health care system is primarily funded through a KRG budget allocation that provides salaries to medical professionals working in the public sector. The budget allocation is also used to pay for medicines, consumables, and investments in health care infrastructure, such as buildings and equipment. But the KRG depends on a payment from the central Iraqi government in Baghdad, equal to 17 percent of its budget- the disbursement of which has not always been timely or dependable. About 6 percent of the KRG budget goes to the public-sector health care system, but about 75 percent of that goes to operating expenses (mostly salaries).

Access to public-sector health care is guaranteed by the KRG draft constitution, but the clinics and hospitals are overcrowded, the doctors are overworked, and the facilities are run down. As a result, many of those who can afford to pay out of pocket turn to physicians in the private sector for care.

In Phase I of the project (beginning in 2010), in addition to modeling future demand as previously described, the RAND team began to analyze the KRG health financing system and briefed KRG leaders on other countries' financing models that might be applicable in the Kurdistan Region of Iraq.

In Phase II (beginning in late 2011), the RAND team assessed the KRG's health care financing system in greater detail, with a focus on how the KRG might move toward a health financing system based on insurance. The research team laid out plans and policy options, as well as questions that would need to be answered in order to move in that direction.

At that time, RAND researchers also began to examine the issue of physician dual practice, which had become standard among KRG physicians during the first Gulf War, when doctors were paid sporadically and were not paid enough to support their families. Most KRG health leaders agreed that dual practice exacerbated the inefficiencies of the health financing system and its effects on the workforce and that the KRG could no longer afford these excessive inefficiencies. With this in mind, the RAND team suggested an initial plan, as well as policy and regulatory options open to the KRG.

In Phase III (beginning in 2013), RAND researchers conducted a series of interviews and focus groups to further analyze this issue and then developed four reform options to minimize or phase out dual practice and detailed steps for their implementation.

Because data were not available to show how much time physicians spent providing services in the public sector, and other data were needed to develop and administer policy changes, RAND researchers gathered these data through interviews and focus groups. The results suggested that, even though physicians were paid for a 35-hour workweek in the public sector, most worked less than half (often far less) that

\section{Most physicians work in both public-sector clinics and private practice to make a living.}
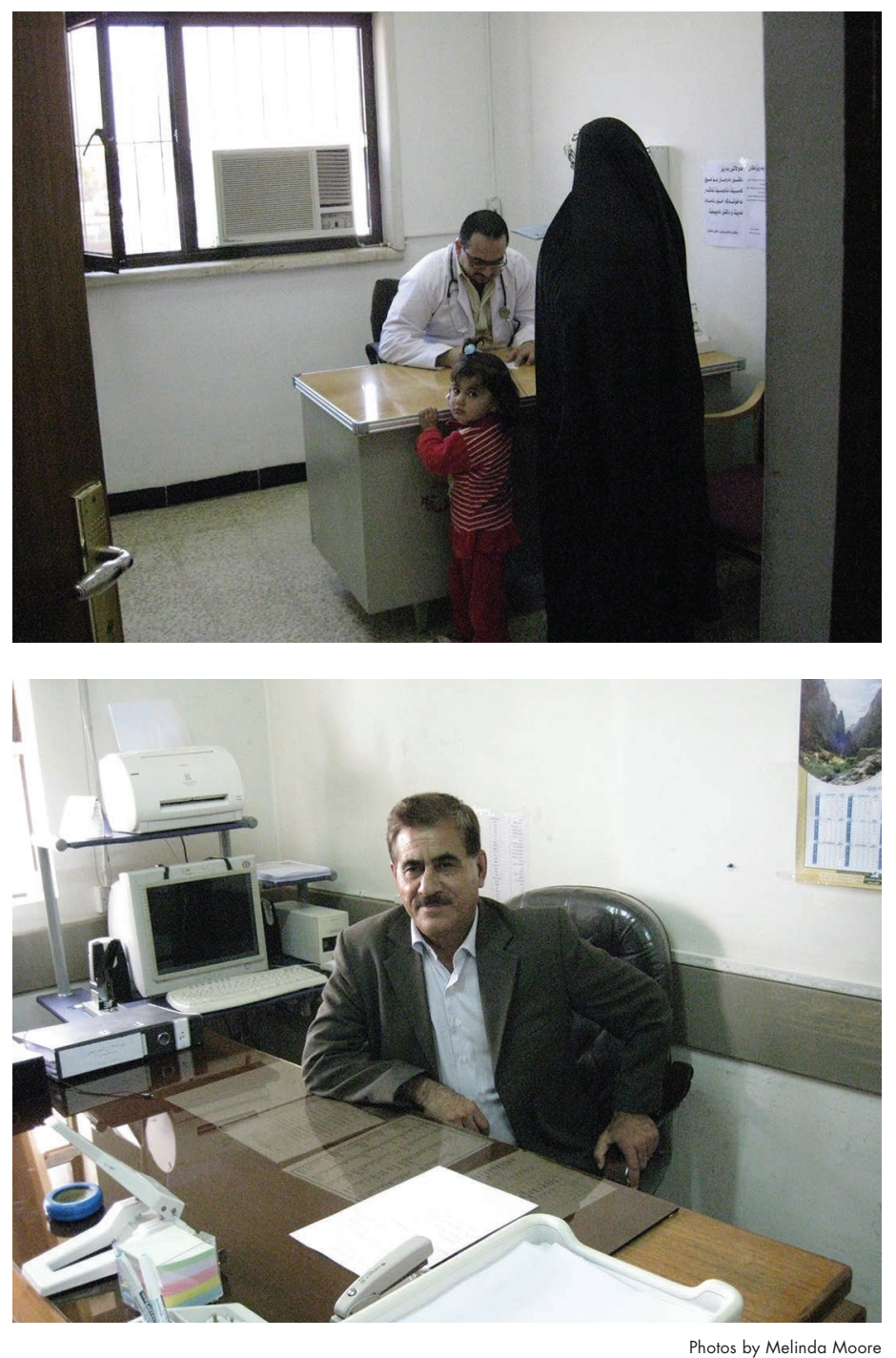
amount of time in the public sector before switching over to work at their private clinics. Physicians reported that this was primarily because their public-sector salaries were too low to sustain their families, and pay in the private sector was many times higher. In addition, doctors reported that public-sector health resources, such as office and operating room space, beds, nursing staff, laboratories, and ancillary services, were inadequate to support longer clinic hours for all doctors.

The RAND team offered four possible solutions to address the dual practice problems:

1. Continue with the status quo but adopt certain regulatory reforms and require new physicians to work exclusively in the public sector for a minimum number of years (for example, three or five years) before becoming eligible to practice in the private sector.

2. Link the number of hours worked to the amount of compensation in the public sector and allow physicians to continue dual practice, but set higher rates of public-sector pay and bonuses through the Ministry of Health to encourage working a full schedule each week.

3. Require physicians to choose public-sector or private-sector practice during the day, but allow them to work in private practice in the evening.

4. Separate public-sector and private practice entirely, and require physicians to commit to one practice environment for a specified length of time, such as three or four years.

All of these options would need to be phased in over time, and physician public-sector compensation would need to be raised under each scenario to be more competitive with the private sector and to embed proper incentives in the system. The RAND team recommended that the KRG adopt Option 4, which called for complete separation of the public and private sectors. Their analysis indicated that this would be the easiest option to implement and the one likely to achieve the greatest efficiencies and flexibility.

\section{Primary Health Care}

Before RAND researchers could offer insights into how the KRG might shore up its primary care system, they first had to understand the current system. The team's initial assessment revealed considerable strengths: Most people lived within 30 minutes of a primary care center, and the total number and types of health care facilities (that is, hospitals and health centers) were sufficient by global standards. At least on the surface, these characteristics suggested that access to health care should be adequate.

However, even though the overall number of primary health care centers was sufficient, the geographic distribution of services provided, staffing, and equipment were uneven. Also problematic: The KRG had not established standards for the minimum number and type of staff to maintain a primary care center or a minimum set of services to be delivered at each type of center. In several centers, laboratory or other equipment was present but not functional, or the center did not have a trained user. Referrals and "handoffs" between providers were not done systematically, potentially leading to poor continuity of care as patients see multiple providers.

Standards for medical professionals were sorely lacking in terms of training, education, and licensing, and there was a complete absence of job descriptions, making oversight and management difficult. Nurses, especially, were undervalued and underutilized and were perceived to have inadequate skills; expectations for their role were unclear, and job descriptions did not exist. Furthermore, sparse data collection left health system managers without enough information to make decisions to allocate resources efficiently and identify problems requiring management attention.

The RAND team suggested setting up a primary care management information system (MIS) as a major step toward addressing these issues. Such a system could help health system managers keep track of basic data on health centers, including the location, number of people to be served, staffing, operations, equipment and its functional status, and services offered - aiming to identify problems and pinpoint needed solutions. The RAND team and the KRG leadership agreed that this primary care MIS would help deliver practical information on which to base future management actions.

To set up the MIS and establish a baseline, RAND researchers collaborated with KRG health leaders to collect data, first through a pilot test in a few primary health care centers and then from 615 centers across the entire region. The RAND team presented their findings to the Minister of Health and Minister of Planning in tables, charts, and maps-the latter providing simple but powerful visualization of the data. One map, for example, showed that dental services might be available at one center, but the nearest dental X-ray machine might be located tens of miles away. Another showed that many centers with computer equipment did not have personnel on hand who understood how to use a computer. Finally, other maps showed that some centers had a lab and specific equipment, but the equipment did not work (see the maps on page 4).

Understanding that these mismatches exist is a critical first step toward addressing the problems, by repairing or procuring equipment, reassigning personnel, and/or providing training so that valuable equipment can be properly used. An MIS can also be used to track improvements over time, as targeted problems with staffing, equipment, and services are resolved.

The MIS is now in the hands of KRG health leaders to institutionalize. It is currently paper-based, but the Minister of Planning and Minister of Health have indicated their interest in creating an online system for both reporting data 
Data visualizations illustrate mismatches in KRG resources-here, mismatches between dental personnel and dental equipment.

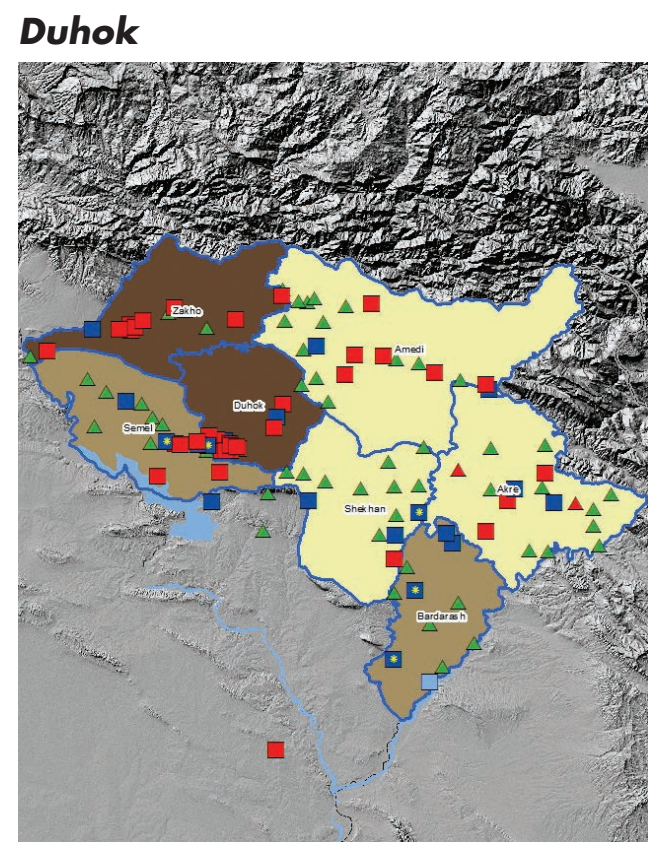

\section{Erbil}

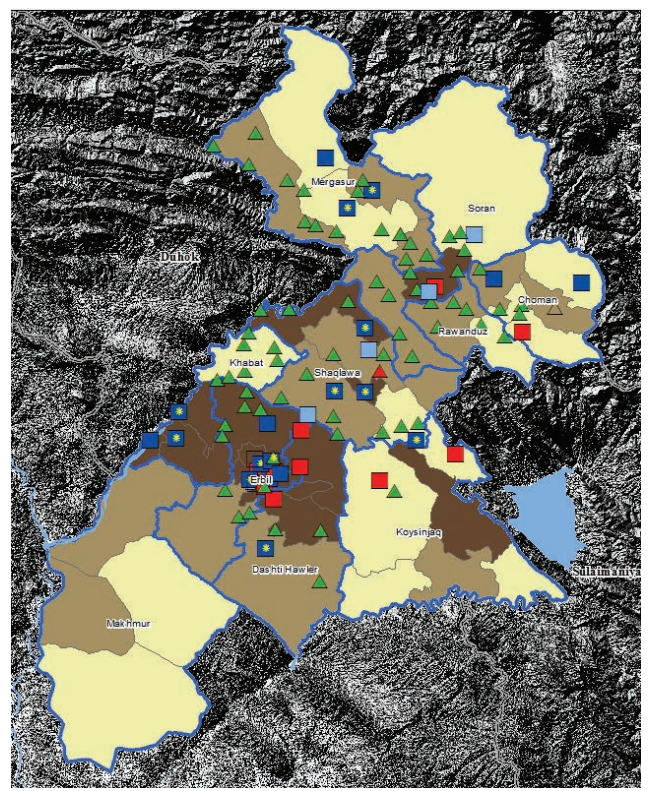

\section{Sulaimaniyah}

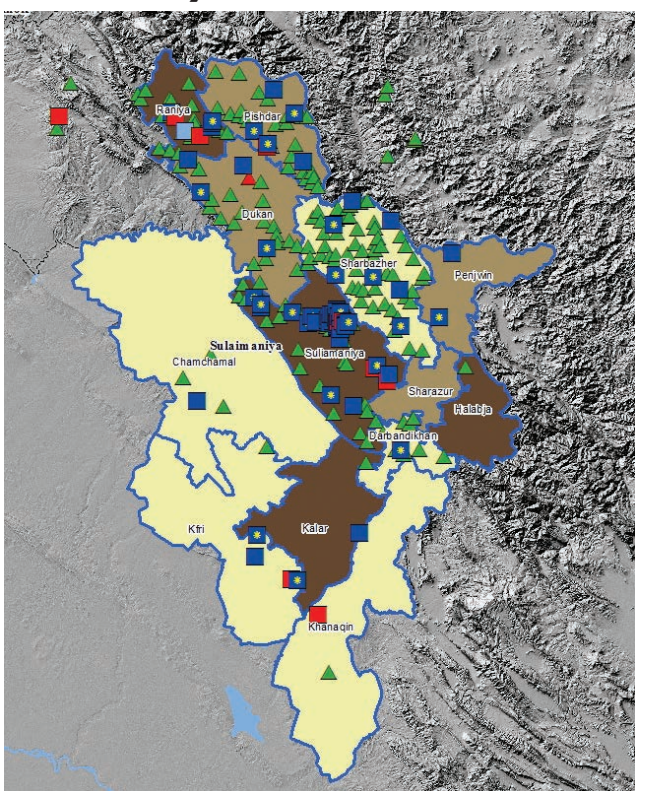

* Main center, dentist, dental X-ray

Main center, dentist, no dental X-ray

Main center, no dentist, dental X-ray

Main center, no dentist, no dental X-ray

Main center, no data

\begin{abstract}
$\triangle$ Sub-center, dentist, dental X-ray
$\Delta$ Sub-center, dentist, no dental X-ray

$\triangle$ Sub-center, no dentist, dental $X$-ray

$\Delta$ Sub-center, no dentist, no dental X-ray

$\triangle$ Sub-center, no data
\end{abstract}

and accessing analyses. Having this system in place is a significant first step toward filling the current gaps in the primary health care system.

\section{Health Care Quality}

Decades of uneven investment in the health care system left it riddled with quality-of-care problems and patient safety concerns, which would need to be addressed to restore the quality of the KRG health system.

Quality health care can be defined in many different ways. The U.S. Institute of Medicine (known as the National Academy of Medicine since July 2015) conceptualizes it as having six domains: equity, safety, effectiveness, efficiency, timeliness, and patient-centeredness. The KRG chose to focus on the safety domain first, to take small steps toward improving quality across the health care system. In Phase II of the project (beginning in 2011), the RAND team worked with policymakers to develop a quality agenda. And in Phase III (beginning in 2013), RAND researchers coordinated a training workshop on patient safety.

RAND researchers worked with the Minister of Health to identify local medical leaders who could participate in a train-the-trainer model of information dissemination. After a multi-day workshop of collaborative education and implementation planning with seven KRG health leaders and hospital managers, the participants would bring their newly acquired knowledge and tools to their home hospitals and localities and share their enthusiasm for practical—and viable-quality reforms.

The initial workshop was held in 2014 in Turkey at the flagship hospital of the Acibadem group, which also had faced quality improvement challenges in prior years. The hospital had gone on to achieve accreditation twice by the Joint Commission International (JCI), one of the world's premier health accreditation organizations. The Kurdish workshop participants built their aspirations of meeting international standards into a vision statement and spent three and a half days viewing presentations and videos; participating in case studies, problem-solving exercises, and group discussions; and learning about the Acibadem hospital's journey and JCI evaluations. The final workshop day focused on change management, framed by the words of one of the participants: "Change begins with just one step. We must begin."

Workshop members established a Proposed Pilot Quality and Patient Safety Improvement Agenda to be implemented over six months, focusing on infection control (hand hygiene), 
patient identification, emergency cart standardization, safe surgery protocols, and completeness and standardization of medical records. At the conclusion of the workshop, participants traveled back to their home institutions, armed with pain assessment forms, patient safety posters, and resources for hand hygiene and medication management, among others, ready to implement change where possible in coordination with government and community leaders.

This workshop has already led to a higher-functioning and higher-quality health care system. The head of the West Erbil Emergency Hospital—one of the participantsreported significant patient safety improvements since the workshop. The gains were achieved through initiatives to use hand-sanitizing gel, containers for sharp surgical items and needles, disposable shoe covers, and patient identification bracelets, along with efforts to improve provider-patient communication and monitor continued quality advances. The RAND team suggested that the KRG consider establishing a new institute for patient safety in Erbil to expand on the knowledge gained and the training successes to date so that the patient quality agenda could be expanded to other facilities in the region.

\section{Moving Forward}

Over the six years of this project, RAND researchers developed long-standing relationships and trust with KRG health leaders, and the resulting plans, options, and recommendations have laid a sturdy foundation for a more robust health care system-consistent with the KRG's vision for 2020. The KRG continues to be pulled into the unrest of the Middle East, intensifying budgetary and critical security needs since the invasion of ISIS, and the influx of internally displaced Iraqis and Syrian refugees. The KRG's resources have become severely constrained, putting the health system under even more stress than in 2010. But the KRG leaders and medical community continue to express a commitment to the best possible health care to all-Kurdish residents, other Iraqis, refugees, and visitors alike-despite these conditions.

Many policy changes have been adopted, while others that have not yet been implemented will remain relevant for
Hand sanitizer, puncture-resistant containers for sharp needles and blades, patient identification bracelets, and shoe covers are low-cost safety interventions that significantly improve health care quality.

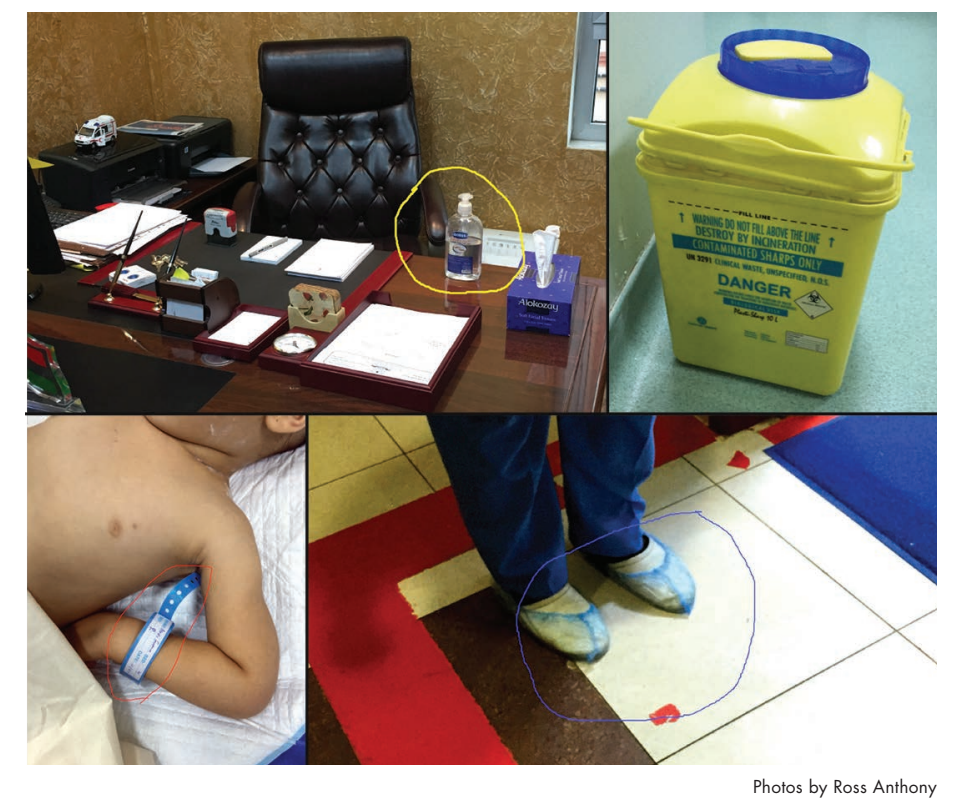

the foreseeable future. The KRG will decide broadly how to proceed with health care financing and can take early steps to address the problem of physician dual practice. Most of the original recommendations related to the primary care system remain pertinent, addressing different aspects of the organization and management of the system, staffing, and information systems. For instance, the KRG could embark on an effort to recruit medical personnel from rural areas where nurses and physicians are in short supply. And the initial momentum for health service quality improvement could be rekindled to expand training locally to other hospitals and to the other quality improvement domains. Once the threat from ISIS is eliminated and the demands of refugees and internally displaced persons ease, the KRG will hopefully again have the resources to address the health reforms recommended by the RAND team to help achieve the region's vision for 2020 . 


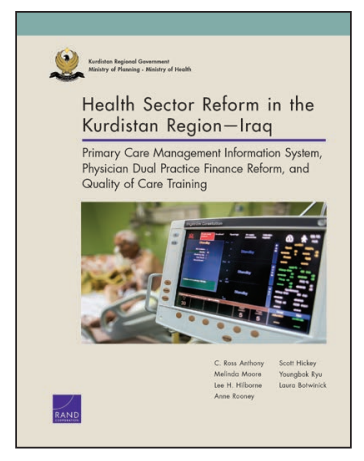

This brief describes work done in RAND Health documented in Health Sector Reform in the Kurdistan Region-Iraq: Primary Care Management Information System, Physician Dual Practice Finance Reform, and Quality of Care Training, by C. Ross Anthony, Melinda Moore, Lee H. Hilborne, Anne Rooney, Scot Hickey, Youngbok Ryu, and Laura Botwinick, RR-1658-KRG, 2017 (available at www.rand.org/t/RR1658). To view this brief online, visit www.rand.org/t/RB9990. The RAND Corporation is a research organization that develops solutions to public policy challenges to help make communities throughout the world safer and more secure, healthier and more prosperous. RAND is nonprofit, nonpartisan, and committed to the public interest. RAND's publications do not necessarily reflect the opinions of its research clients and sponsors. RAND ${ }^{\circledR}$ is a registered trademark. ๑ RAND 2017

Limited Print and Electronic Distribution Rights: This document and trademark(s) contained herein are protected by law. This representation of RAND intellectual property is provided for noncommercial use only. Unauthorized posting of this publication online is prohibited. Permission is given to duplicate this document for personal use only, as long as it is unaltered and complete. Permission is required from RAND to reproduce, or reuse in another form, any of our research documents for commercial use. For information on reprint and linking permissions, please visit www.rand.org/pubs/permissions.html. 